
\title{
$\begin{array}{ll}\text { Research Square } & \begin{array}{l}\text { Preprints are preliminary reports that have not undergone peer review. } \\ \text { They should not be considered conclusive, used to inform clinical practice, } \\ \text { or referenced by the media as validated information. }\end{array}\end{array}$
}

\section{Development and Psychometrics Test of Home Blood Pressure Monitoring Perception Scale for Patients With Chronic Kidney Disease}

\author{
Jing Zheng \\ Guangdong Pharmaceutical University \\ Yamin Wang \\ Sun Yat-Sen University https://orcid.org/0000-0001-6289-7528 \\ Wenbo Zhao \\ Third Affiliated Hospital of Sun Yat-Sen University \\ Huiqun Li \\ Third Affiliated Hospital of Sun Yat-Sen University \\ Hongli Shang \\ Third Affiliated Hospital of Sun Yat-Sen University \\ Qianqian Pei \\ Guangdong Pharmaceutical University \\ Yanru Chen ( $\nabla$ chenyr07@163.com) \\ Third Affiliated Hospital of Sun Yat-Sen University https://orcid.org/0000-0003-4229-9154
}

\section{Research Article}

Keywords: chronic kidney disease, home blood pressure monitoring, perception, psychometrics, reliability, validity

Posted Date: June 22nd, 2021

DOI: https://doi.org/10.21203/rs.3.rs-628191/v1

License: (a) (i) This work is licensed under a Creative Commons Attribution 4.0 International License. Read Full License 


\section{Abstract}

Background: Home blood pressure monitoring (HBPM) has been proved to be beneficial to blood pressure control for both patients with hypertension and patients with chronic kidney disease (CKD). However, what are the psychodynamic predictors like perception for the establishment and persistence of HBPM have not been deeply explored, and there is a lack of instruments for assessing psychodynamic characteristics on HBPM from patients' perspectives, which has limited the in-depth understanding of HBPM behavior. The study aimed to develop an instrument for evaluating HBPM perception in patients with CKD, and to test the reliability and validity of the instrument.

Methods: The original item pool of the HBPM perception scale was developed according to the framework of the health promotion model and literature review. The psychometric characteristics of the instrument were examined with a sample of 436 CKD patients in China. Internal consistency reliability, split-half reliability, test-retest reliability and construct reliability were used to verify the reliability of the scale. And content validity, construct validity and criterion-related validity were used to test the validity of the scale.

Results: The expert consultation showed satisfactory content validity of the HBPM perception scale and produced a first draft of the survey with 43 items. By exploratory factor analysis and confirmatory factor analysis (CFA), we found evidence for the construct validity of the following factors: perceived benefits of HBPM, perceived barriers of HBPM, perceived self-efficacy of HBPM, situational influences and commitment to a plan of HBPM, and immediate competing demands and preferences. The finalized five-component HBPM perception scale has 27 items. CFA suggested the model fit the data well $\left(\mathbb{\Xi}^{2}=679.649, d f=310, \mathbb{\Xi}^{2} / d f=2.192\right.$, root mean square error of approximation $=0.074$, confirmatory fit index $=0.902$ ). The HBPM perception scale was positively associated with the SelfEfficacy for Managing Chronic Disease 6-item Scale ( $r=0.256, p \otimes 0.001)$. The Cronbach's a coefficient of all dimensions was above 0.750 , the split-half reliability was above 0.624 , and the test-retest reliability was above 0.749 . The construct reliability of dimensions ranged from 0.749 to 0.951 .

Conclusion Given reasonable psychometric properties, the HBPM perception scale is a valid and reliable instrument that can be used to assess the perception of HBPM.

\section{Introduction}

Chronic kidney disease (CKD), a group of diseases with chronic progressive deterioration of renal function and structure, with high morbidity, high mortality and high medical expenditure, has become a chronic non-communicable disease that seriously affects global public health. CKD has a high global prevalence of between $11-13 \%$, with the majority stage $3^{1}$. The prevalence of CKD among Chinese adults is $10.8 \%$, with an estimated 119.5 million CKD patients nationwide ${ }^{2}$, and the prevalence of CKD in people over 45 years of age was $11.5 \%{ }^{3}$. The results of the global burden of disease research program ${ }^{4}$ showed that in $2013,956,200$ patients died of CKD worldwide, with a 1.34-fold increase since 1990. Cardiovascular events are the main cause of death of patients with CKD in the world, accounting for more than $60 \%{ }^{5}$. Hypertension is the most common cardiovascular complication in patients with CKD. The prevalence of hypertension in patients with CKD in the United States was $>60 \%$, and the prevalence of hypertension in patients with stage 3 and above was as high as $85.7 \%$ in the U.S. ${ }^{6}$. In China, the prevalence of hypertension in non-dialysis CKD patients is nearly $70 \%{ }^{7}$. With the decline of renal function, the prevalence of hypertension in patients with CKD gradually increased, and was as high as $91 \%$ in CKD stage $5^{7}$.

Hypertension is one of the major risk factors for the progression of CKD and cardiovascular disease. Blood pressure level and cardiovascular risk showed a continuous, independent and direct positive correlation ${ }^{8}$. Controlling blood pressure can reduce the risk of cardiovascular diseases such as atherosclerosis, heart failure, as well as cardiovascular events and vascular death ${ }^{9}$. Currently, patients' blood pressure is mainly controlled by medication treatment ${ }^{10}$ and non-drug therapy ${ }^{11}$ (such as no smoking, weight control, reduce mental stress). But blood pressure control in patients with CKD remains unsatisfactory. Literature reports that the control rate of hypertension in patients with CKD was $67.1 \%$ for the standard of blood pressure $<140 / 90 \mathrm{mmHg}$, and $46.1 \%$ for the standard of blood pressure $<130 / 80 \mathrm{mmHg}$ in the U.S. ${ }^{6}$. In China, the control rate of blood pressure $<140 / 90 \mathrm{mmHg}$ in non-dialysis CKD patients was $33.1 \%$, and the control rate of blood pressure $<130 / 80 \mathrm{mmHg}$ was only $14.1 \%{ }^{7}$. In addition to antihypertensive drugs, how to help patients effectively establish the scientific lifestyle and related health promotion behaviors has become a key and urgent need to be addressed for non-drug therapy. 
Blood pressure monitoring plays an essential role in the diagnosis, condition evaluation, curative effect evaluation and prognosis judgment of hypertension. Among them, home blood pressure monitoring (HBPM) has the advantages of strong practicability and maneuverability (simple operation, low cost, strong repeatability) ${ }^{12,13}$, and its role in hypertension monitoring has been increasingly valued. At present, clinical practice guidelines in China ${ }^{8}$, the United States ${ }^{14}$, Japan ${ }^{15}$, Europe ${ }^{16}$ and other countries and regions recommend HBPM for hypertensive patients for efficacy evaluation of antihypertensive drugs. HBPM can effectively predict the risk of cardiovascular events, stroke and death in patients with hypertension ${ }^{17}$. Meanwhile, HBPM behavior can also be regarded as a health promotion behavior. Hypertensive patients with HBPM behavior have higher level of understanding of antihypertensive drugs, higher medication compliance, and more satisfactory blood pressure control ${ }^{18,19}$.

Although HBPM has important value for CKD therapy, HBPM in patients with CKD has not been studied in-depth, and the subjects of the HBPM study are mainly hypertensive patients. In the hypertensive population, only about $50 \%$ had their blood pressure monitored at home ${ }^{20}$. Demographic factors, such as age, gender and education level have been identified associating with HBPM behavior of hypertensive patients in multiple studies ${ }^{20-24}$. From the patient's experiences, the main reasons for not measuring blood pressure at home include failing to recognize the benefits of $\mathrm{HBPM}^{25}$, lacking skills to operate the device ${ }^{25}$, having difficulty adhering to time limits for $\mathrm{HBPM}^{26}$, and holding the belief that their blood pressure measured by themselves is not as accurate as the doctor's ${ }^{27,28}$, which hinder patients to perform HBPM regularly. However, studies on the promotion and adherence of HBPM in CKD patients are not as rich as that in patients with hypertension. Therefore, it is very necessary to explore the psychodynamic mechanism and action process of HBPM in patients with CKD, so as to improve the adherence of HBPM for these patients. Moreover, studies have investigated patients' psychodynamic predictors to monitor home blood pressure mainly through single item questions ${ }^{25,26,29}$, or interview patients for information ${ }^{18,27,28,30}$. The specific instruments to assess the psychodynamic predictors of patients' HBPM behavior is still lacking until now.

The health promotion model (HPM), as a comprehensive theoretical model, be able to identify complex biological, psychological and social processes associated with behavior change, and it can be used to explain various health promotion behaviors ${ }^{31,32}$. The model is composed of three groups of ten categories of factors that influence health behaviors, which includes personal characteristics and experiences (i.e., pre-related behaviors, personal factors), behavior-specific cognitions and affect (i.e., perceived benefits of action, perceived barriers of action, perceived self-efficacy, situational influences, interpersonal influences and activity-related affect), and desirable health promotion behavior (i.e., commitment to a plan of action and immediate competing demands and preferences) ${ }^{32}$. The health promotion model had been widely used to predict the establishment of behavioral predictors such as hearing protection ${ }^{33}$, regular breakfast eating ${ }^{34}$, and physical activity in adolescents ${ }^{31}$ and patients with chronic disease like chronic kidney disease, diabetes and stroke $29,31,35$. And in previous studies, the health promotion model had demonstrated high levels of predictive power. Wu and Pender ${ }^{36}$ studied the determinants of physical activity based on health promotion models, and the results showed that variables accounted for $30 \%$ of the variance in physical activity, and the perceived self-efficacy was the strongest predictor of physical activity among adolescents in Taiwan.

Since monitoring home blood pressure is a health promotion behavior, the intervention program based on the theory of health promotion behavior will be more targeted and systematic. This study assumes that the scale based on the health promotion model can effectively evaluate and predict HBPM behavior. The purpose of this study was to develop the home blood pressure monitoring perception scale and conduct reliability and validity tests so as to provide a reliable instrument for medical staff to assess the psychodynamic predictors of HBPM.

\section{Methods}

\section{Participants}

The convenience sample was selected from the department of nephrology of two tertiary hospitals in Guangdong province and collected data from March to October 2019. This study was approved by the ethics committee of the affiliated hospital of Sun Yat-sen University in accordance with the Declaration of Helsinki. Patients were included with the criteria: (1) diagnosed with CKD, the diagnostic criteria are derived from the Guidelines of Kidney Disease: Improving Global Outcomes; (2) diagnosed with hypertension according to the 2018 Chinese Guidelines for the Management of Hypertension: systolic blood pressure $\geq 140 \mathrm{mmHg}$ and/or diastolic blood pressure $\geq 90 \mathrm{mmHg}$ without receiving antihypertensive medication; (3) at least 18 years old; (4) volunteer to join in this study, 
and sign the informed consent. The exclusion criteria included: (1) dyskinesia of upper limbs; (2) upper-extremity amputations; (3) high anxiety or history of mental disorders; (4) cognitive impairments; and (5) people with severe visual or hearing impairments.

A total of 436 patients with CKD stage $1-5$, aged $52.77 \pm 14.45$ years (range $20-87$ years), completed the measures. CKD stage $1-4$ patients were 17 (3.9\%), 12 (2.8\%), 21 (4.8\%) and 9 (2.1\%), respectively. There were 33 (7.6\%) non-dialysis CKD-5 patients, 323 (74.1\%) hemodialysis patients and 21 (4.8\%) peritoneal dialysis patients. Among them, there were 284 males (65.1\%) and 152 females (34.9\%);114 (26.1\%) had primary school or below, 127 (29.1\%) had completed junior high school, 111 (25.5\%) had completed high school, and $84(19.3 \%)$ had earned a university degree or above.

Of the 436 patients surveyed in this study, 89.91\% (392) of patients had a blood pressure measuring device at home. Among these patients, electronic sphygmomanometer was the main type of blood pressure measuring device $(97.45 \%, 382)$. Blood pressure was mainly measured in the upper arm $(92.35 \%, 362) .65 .83 \%(287)$ of patients had their blood pressure measured at least once a week. The mean office systolic blood pressure was $147.50 \pm 21.19 \mathrm{mmHg}$, and the mean office diastolic blood pressure was $87.30 \pm$ $14.22 \mathrm{mmHg}$. There were $358(82.1 \%)$ patients using at least one type of antihypertensive medication, and more than half of the patients $(56.9 \%)$ took a combination of two or more antihypertensive drugs to control blood pressure. Specific participant characteristics were reported in the previous article ${ }^{37}$.

\section{Instruments}

The questionnaire consisted of three parts, which were the home blood pressure monitoring perception scale, the Self-Efficacy for Managing Chronic Disease 6-item Scale and the characteristics questionnaires.

\section{Home Blood Pressure Monitoring Perception Scale}

This scale was developed through item pool formation, expert consultation and item selection. Based on the health promotion model, we generated the item pool for the HBPM perception scale after reviewing a large pool of literature and conducting research group discussions, which consisted of seven aspects and 58 items. The HBPM perception scale is a self-report scale.

A panel of eight experts was employed to conduct two rounds of reviews of the item pool of the HBPM perception scale. Experts had various academic backgrounds, including nephrology, cardiology, nursing, and education. They aged $24 \sim 54$ (37.3 \pm 9.1$)$ years old and had clinical or academic experiences for $13.0 \pm 11.2$ years. There were two males and six females; three had doctoral degrees, one had master's degree; three of them hold associate senior titles and three hold intermediate titles. Experts were asked to evaluate the importance, relevance, and linguistic expression of each item, and were encouraged to add necessary items to the item pool. The importance and relevance were evaluated with a Likert 5-rating scale and a Likert 4-rating scale, respectively. The active coefficient of experts in the two rounds was $100 \%$. The expert authority coefficient was 0.84 , and the coordination coefficients of the two rounds of experts were 0.206 and 0.746 , respectively. The full-score ratio $\geq 50 \%$, with the average score of importance assignment $\geq 4.00$, itemlevel content validity index $(\mathrm{I}-\mathrm{CVI}) \geq 0.78$ was considered as the item selection standard ${ }^{[10]}$. After expert consultation and discussion by the research group, the draft of the HBPM perception scale was formed, including 43 items. Likert 5 rating was used in the scale, including "strongly disagree $=1$, disagree $=2$, neutrality $=3$, agree $=4$, strongly agree $=5 "$.

\section{Self-Efficacy for Managing Chronic Disease 6-item Scale}

This scale has been used in chronic diseases to measure patients' self-efficacy ${ }^{38}$. The scale consists of 6 items with each item is scored on a scale of 1 to 10 . The average score of the items represents the level of self-efficacy, and the higher the score, the better the self-efficacy. In this study, the scale was used to as a criterion, and criterion-related validity was calculated by analyzing its correlation with this developed scale.

\section{Characteristics Questionnaire}

The questionnaire was composed of demographic and sociological information of patients (gender, age, level of education), diseaserelated information such as office blood pressure and the use of antihypertensive drugs, etc.

\section{Data Collection}

Participants were asked to complete the questionnaires on the spot. The investigator explained the purpose, content and ethical issues of the study to patients. Patients participating in the study all signed informed consent forms. The patients completed the 
questionnaire by themselves. A total of 436 questionnaires were issued, and 436 were effectively collected, with an effective collected rate of $100 \%$. Thus, 436 valid respondents were included in the data analyses. Twenty participants completed the questionnaires again two weeks after the first survey.

\section{Data Analysis}

Data analyses were performed on the basis of three samples. First, the data collected from 436 participants were randomly split into two halves. The first half of the participants (sample 1) was used for item analysis and selection and exploratory factor analysis (EFA). Item frequency analysis ${ }^{39}$, coefficient of variation (C.V.), critical ratio (C.R.), item-total correlation, corrected item-total correlation (CITC), internal consistency reliability coefficient, commonalities value and factor loading ${ }^{40}$ were adopted to analyze and screen items, items that meet three or more standards were considered to be retained ${ }^{41}$. The standards for the above coefficients are shown in table 1. Sampling suitable for factor analysis was evaluated with the Kaiser-Meyer-Olkin (KMO) measure and Bartlett's Test of Sphericity. Principal component analysis (PCA) and varimax rotation method were performed to decide the optimal number of components, and the number of extraction factors was determined by the eigenvalue (greater than 1 ) and scree plot. Items with factor loading values greater than 0.40 and no repeat load (the same item has a factor loading greater than 0.4 in 2 or more components) were kept.

Sample 2 included the other half of the participants, was used for validity and reliability test. Confirmatory factor analysis (CFA) was adopted to test the construct validity. Content validity and criterion-related validity were also analyzed to test the scale validity $40,42,43$. At the same time, the discriminability of the scale was verified in patients with different monitoring frequencies. Internal consistency reliability, split-half reliability, test-retest reliability and construct reliability were used to test the reliability of the scale ${ }^{40,44}$. Sample 3 , which included 20 participants, was used to gauge test-retest reliability. SPSS 20.0 and Amos 23.0 were used for data analysis.

\section{Results}

\section{Item Analysis and Selection}

There was no item with more than $80 \%$ distribution on an option. The other analysis results of the items are shown in table 1 . After analysis, item $23,24,34,41$, and 42 failed to meet the standard of 3 or more, therefore they were considered to delete. 
Table 1

The analysis results of the items of the first draft with 43 items $₫ n=218$ )

\begin{tabular}{|c|c|c|c|c|c|c|c|c|c|c|}
\hline Item & $\overline{\mathrm{x}}$ & $S$ & C.V. & C.R. & $\begin{array}{l}\text { Item-total } \\
\text { correlation }\end{array}$ & CITC & $\begin{array}{l}\text { Cronbach's } \\
\text { a if item } \\
\text { deleted }\end{array}$ & Commonalities & $\begin{array}{l}\text { Factor } \\
\text { loading }\end{array}$ & $\begin{array}{l}\text { Substandard } \\
\text { quantity }\end{array}$ \\
\hline 1 & 3.88 & 0.806 & 0.208 & $10.431^{\star *}$ & $0.718^{\star \star}$ & 0.700 & 0.937 & 0.554 & 0.744 & 0 \\
\hline 2 & 3.82 & 0.906 & 0.237 & $14.449^{\star \star}$ & $0.770^{* *}$ & 0.753 & 0.937 & 0.654 & 0.809 & 0 \\
\hline 3 & 3.80 & 0.914 & 0.241 & $11.814^{\star \star}$ & $0.712^{* *}$ & 0.691 & 0.937 & 0.560 & 0.748 & 0 \\
\hline 4 & 3.49 & 1.026 & 0.294 & $12.393^{\star \star}$ & $0.668^{* *}$ & 0.641 & 0.937 & 0.481 & 0.694 & 0 \\
\hline 5 & 3.78 & 0.911 & 0.241 & $12.800^{\star \star}$ & $0.733^{* *}$ & 0.714 & 0.937 & 0.604 & 0.777 & 0 \\
\hline 6 & 3.61 & 0.925 & 0.256 & $14.527^{\star \star}$ & $0.729^{* \star}$ & 0.708 & 0.937 & 0.599 & 0.774 & 0 \\
\hline 7 & 3.72 & 0.950 & 0.255 & $11.726^{\star *}$ & $0.673^{* *}$ & 0.649 & 0.937 & 0.524 & 0.724 & 0 \\
\hline 8 & 4.13 & 0.683 & 0.165 & $5.295^{\star \star}$ & $0.453^{* \star}$ & 0.429 & 0.939 & 0.182 & 0.426 & 2 \\
\hline 9 & 3.91 & 0.854 & 0.218 & $6.630^{\star \star}$ & $0.458^{* *}$ & 0.428 & 0.939 & 0.185 & 0.431 & 2 \\
\hline 10 & 3.83 & 0.889 & 0.232 & $4.371^{\star \star}$ & $0.363^{* \star}$ & 0.328 & 0.940 & 0.115 & 0.339 & 4 \\
\hline 11 & 3.28 & 1.163 & 0.355 & $11.645^{\star \star}$ & $0.651^{\star *}$ & 0.620 & 0.937 & 0.437 & 0.661 & 0 \\
\hline 12 & 3.85 & 0.873 & 0.227 & $7.402^{\star \star}$ & $0.577^{\star \star}$ & 0.551 & 0.938 & 0.312 & 0.559 & 0 \\
\hline 13 & 3.47 & 1.087 & 0.313 & $9.382^{* \star}$ & $0.573^{* \star}$ & 0.539 & 0.938 & 0.289 & 0.537 & 0 \\
\hline 14 & 3.56 & 0.997 & 0.280 & $6.050^{\star *}$ & $0.450^{\star *}$ & 0.413 & 0.939 & 0.188 & 0.433 & 2 \\
\hline 15 & 3.20 & 1.122 & 0.351 & $6.388^{* *}$ & $0.463^{* *}$ & 0.422 & 0.939 & 0.170 & 0.413 & 2 \\
\hline 16 & 3.63 & 1.009 & 0.278 & $9.348^{* *}$ & $0.628^{\star *}$ & 0.600 & 0.938 & 0.345 & 0.587 & 0 \\
\hline 17 & 3.97 & 0.811 & 0.204 & $4.368^{\star \star}$ & $0.376^{* *}$ & 0.344 & 0.939 & 0.118 & 0.343 & 4 \\
\hline 18 & 3.89 & 0.830 & 0.213 & $7.223^{\star \star}$ & $0.562^{\star *}$ & 0.535 & 0.938 & 0.302 & 0.549 & 0 \\
\hline 19 & 3.53 & 1.039 & 0.294 & $11.631^{\star \star}$ & $0.716^{\star \star}$ & 0.692 & 0.937 & 0.510 & 0.714 & 0 \\
\hline 20 & 3.60 & 1.017 & 0.283 & $12.130^{\star \star}$ & $0.736^{* *}$ & 0.714 & 0.937 & 0.553 & 0.744 & 0 \\
\hline 21 & 3.44 & 1.034 & 0.301 & $12.887^{\star \star}$ & $0.734^{\star \star}$ & 0.711 & 0.937 & 0.555 & 0.745 & 0 \\
\hline 22 & 3.50 & 1.013 & 0.289 & $12.379^{\star \star}$ & $0.726^{* *}$ & 0.703 & 0.937 & 0.564 & 0.751 & 0 \\
\hline 23 & 3.76 & 0.858 & 0.228 & -0.586 & 0.035 & -0.003 & 0.942 & 0.003 & -0.052 & 6 \\
\hline 24 & 3.11 & 1.083 & 0.348 & -0.760 & 0.015 & -0.033 & 0.943 & 0.008 & -0.091 & 6 \\
\hline 25 & 3.69 & 0.892 & 0.242 & $4.477^{* *}$ & $0.457^{* *}$ & 0.425 & 0.939 & 0.172 & 0.415 & 2 \\
\hline 26 & 3.83 & 0.818 & 0.214 & $5.856^{\star *}$ & $0.520^{\star *}$ & 0.493 & 0.938 & 0.217 & 0.466 & 0 \\
\hline 27 & 4.03 & 0.692 & 0.172 & $6.186^{\star \star}$ & $0.460^{\star *}$ & 0.435 & 0.939 & 0.217 & 0.466 & 0 \\
\hline 28 & 3.61 & 1.078 & 0.299 & $14.314^{\star *}$ & $0.679^{\star *}$ & 0.652 & 0.937 & 0.500 & 0.707 & 0 \\
\hline 29 & 3.23 & 1.074 & 0.333 & $12.290^{\star \star}$ & $0.614^{\star \star}$ & 0.583 & 0.938 & 0.415 & 0.644 & 0 \\
\hline 30 & 3.44 & 0.964 & 0.280 & $6.389^{\star \star}$ & $0.470^{\star \star}$ & 0.436 & 0.939 & 0.213 & 0.461 & 0 \\
\hline
\end{tabular}




\begin{tabular}{|c|c|c|c|c|c|c|c|c|c|c|}
\hline 31 & 2.80 & 1.114 & 0.398 & $9.683^{* *}$ & $0.575^{\star \star}$ & 0.541 & 0.938 & 0.364 & 0.603 & 0 \\
\hline 32 & 3.44 & 1.115 & 0.324 & $7.813^{\star \star}$ & $0.544^{\star \star}$ & 0.507 & 0.938 & 0.291 & 0.539 & 0 \\
\hline 33 & 2.78 & 1.154 & 0.415 & $9.296^{\star \star}$ & $0.568^{* *}$ & 0.532 & 0.938 & 0.354 & 0.595 & 0 \\
\hline 34 & 3.64 & 1.008 & 0.277 & $1.651^{\star \star}$ & $0.214^{\star \star}$ & 0.171 & 0.941 & 0.017 & 0.130 & 6 \\
\hline 35 & 3.96 & 0.811 & 0.205 & $9.109^{\star \star}$ & $0.680^{\star *}$ & 0.660 & 0.937 & 0.471 & 0.686 & 0 \\
\hline 36 & 3.23 & 1.122 & 0.347 & $10.193^{\star \star}$ & $0.599^{\star \star}$ & 0.566 & 0.938 & 0.386 & 0.621 & 0 \\
\hline 37 & 4.04 & 0.816 & 0.202 & $7.393^{\star \star}$ & $0.608^{\star \star}$ & 0.584 & 0.938 & 0.372 & 0.610 & 0 \\
\hline 38 & 3.24 & 1.176 & 0.363 & $12.124^{\star \star}$ & $0.697^{\star *}$ & 0.669 & 0.937 & 0.509 & 0.713 & 0 \\
\hline 39 & 2.83 & 1.124 & 0.397 & $9.549^{* \star}$ & $0.607^{\star \star}$ & 0.574 & 0.938 & 0.414 & 0.643 & 0 \\
\hline 40 & 2.66 & 1.062 & 0.399 & $7.306^{* *}$ & $0.435^{\star *}$ & 0.396 & 0.939 & 0.207 & 0.455 & 0 \\
\hline 41 & 2.97 & 1.177 & 0.396 & $2.196^{*}$ & $0.228^{\star *}$ & 0.178 & 0.941 & 0.026 & 0.162 & 6 \\
\hline 42 & 3.49 & 0.956 & 0.274 & $2.197^{\star}$ & $0.249^{\star *}$ & 0.208 & 0.940 & 0.022 & 0.150 & 5 \\
\hline 43 & 3.80 & 0.881 & 0.232 & $3.549^{* *}$ & $0.279^{\star *}$ & 0.242 & 0.940 & 0.075 & 0.274 & 4 \\
\hline Standard & - & - & $\geq 0.15$ & $\geq 3.00$ & $\geq 0.40$ & $\geq 0.40$ & $\nabla 0.94$ & $\geq 0.20$ & $\geq 0.45$ & - \\
\hline \multicolumn{11}{|c|}{ Abbreviations: C.V., coefficient of variation; C.R., critical ratio; CITC, corrected item-total correlation. } \\
\hline
\end{tabular}

\section{Exploratory Factor Analysis}

The KMO index was 0.903 , and the Bartlett spherical test chi-square value reached statistical significance $\left(\chi^{2}=6050.194, p<0.001\right)$, indicating that it was suitable for factor analysis. There were 9 factors whose eigenvalue of initial load matrix was greater than 1 , and the cumulative contribution rate of variance reached $72.669 \%$.

According to the results, 5 items with factor loading less than 0.4 (item 25, 27, 30, 35, 43) were deleted. Items 22,26,29,37 with loads greater than 0.4 above two factors were deleted. Item 8,11 with loads more than 0.4 on at least two factors, but these two items played an important role in the HBPM behavior of patients during the investigation through communication with patients. Meanwhile, the study in patients with hypertension suggested that the price of the sphygmomanometer and the degree of mastery of HBPM methods are important factors affecting patients' HBPM behavior. Therefore, these two items were decided to keep after expert discussion. At the same time, item 28 has highly similar meaning with item 39 in the affiliation factor, so item 28 was deleted. Finally, there were 7 factors whose eigenvalues of the structural matrix are greater than 1, and the cumulative contribution rate of variance reaches $74.373 \%$ (Table 2). The factor loadings and structure were showed in Table 3. 
Table 2

Total Variance Explained of 28 items $(n=218)$

\begin{tabular}{|c|c|c|c|c|c|c|}
\hline \multirow[t]{2}{*}{ Dimension(component) } & \multicolumn{3}{|c|}{ Initial Eigenvalues } & \multicolumn{3}{|c|}{$\begin{array}{l}\text { Extracted Sum of Squared } \\
\text { loadings }\end{array}$} \\
\hline & Total & $\begin{array}{l}\text { Variance } \\
(\%)\end{array}$ & Cumulative(\%) & Total & $\begin{array}{l}\text { Variance } \\
(\%)\end{array}$ & $\begin{array}{l}\text { Cumulative } \\
(\%)\end{array}$ \\
\hline Perceived benefit of HBPM (F1) & 10.993 & 39.260 & 39.260 & 5.679 & 20.283 & 20.283 \\
\hline Perceived self-efficacy of HBPM (F2) & 2.359 & 8.425 & 47.686 & 3.406 & 12.163 & 32.447 \\
\hline Situational influences (F3) & 2.203 & 7.866 & 55.552 & 2.605 & 9.304 & 41.751 \\
\hline $\begin{array}{l}\text { Commitment to a plan of HBPM and immediate } \\
\text { competing demands and preferences (F4) }\end{array}$ & 1.791 & 6.396 & 61.948 & 2.550 & 9.108 & 50.859 \\
\hline \multicolumn{7}{|l|}{ Perceived barriers of HBPM (F5-F7) } \\
\hline F5 & 1.352 & 4.829 & 66.777 & 2.541 & 9.076 & 59.935 \\
\hline F6 & 1.097 & 3.917 & 70.694 & 2.442 & 8.723 & 68.658 \\
\hline F7 & 1.030 & 3.679 & 74.373 & 1.600 & 5.715 & 74.373 \\
\hline
\end{tabular}


Table 3

Rotated Component Matrix of 28 items a $(n=218)$

\section{Component}

\begin{tabular}{|c|c|c|c|c|c|c|c|}
\hline & \multirow{2}{*}{$\begin{array}{l}\text { Perceived } \\
\text { benefit of } \\
\text { HBPM }\end{array}$} & $\begin{array}{l}\text { Perceived } \\
\text { self- } \\
\text { efficacy } \\
\text { of HBPM }\end{array}$ & $\begin{array}{l}\text { Situational } \\
\text { influences }\end{array}$ & $\begin{array}{l}\text { Commitment to a } \\
\text { plan of HBPM and } \\
\text { immediate } \\
\text { competing demands } \\
\text { and preferences }\end{array}$ & \multicolumn{3}{|c|}{$\begin{array}{l}\text { Perceived barriers of } \\
\text { HBPM }\end{array}$} \\
\hline & & $\mathrm{F} 2$ & F3 & $\mathrm{F} 4$ & F5 & F6 & F7 \\
\hline $\begin{array}{l}\text { 5.HBPM helps control my disease } \\
\text { (such as reducing my risk of coronary } \\
\text { heart disease or stroke). }\end{array}$ & 0.873 & 0.151 & 0.112 & 0.155 & 0.079 & 0.185 & 0.056 \\
\hline $\begin{array}{l}\text { 6.HBPM can improve my quality of } \\
\text { life. }\end{array}$ & 0.828 & 0.248 & 0.117 & 0.192 & 0.068 & 0.082 & 0.099 \\
\hline $\begin{array}{l}\text { 3. HBPM helps me take my medicine } \\
\text { as directed. }\end{array}$ & 0.810 & 0.104 & 0.180 & 0.113 & 0.241 & 0.098 & 0.058 \\
\hline $\begin{array}{l}\text { 2.HBPM helps me control blood } \\
\text { pressure. }\end{array}$ & 0.801 & 0.195 & 0.166 & 0.204 & 0.187 & 0.186 & 0.034 \\
\hline $\begin{array}{l}\text { 7.HBPM helps me adjust my lifestyle } \\
\text { (diet, exercise, etc.). }\end{array}$ & 0.773 & 0.241 & 0.182 & 0.112 & -0.040 & 0.144 & 0.184 \\
\hline $\begin{array}{l}\text { 4.HBPM made me feel like I was } \\
\text { working with my doctor to decide on } \\
\text { a treatment. }\end{array}$ & 0.761 & 0.167 & 0.087 & 0.229 & 0.176 & -0.085 & 0.099 \\
\hline $\begin{array}{l}\text { 1.Home blood pressure monitoring is } \\
\text { a good indicator of how my blood } \\
\text { pressure fluctuates. }\end{array}$ & 0.665 & 0.190 & 0.237 & 0.114 & 0.256 & 0.121 & 0.099 \\
\hline $\begin{array}{l}20 . I \text { am confident that I will be able to } \\
\text { monitor my blood pressure at home } \\
\text { for the long term. }\end{array}$ & 0.344 & 0.852 & 0.171 & 0.134 & 0.177 & 0.041 & 0.003 \\
\hline $\begin{array}{l}19 . I \text { am confident that I can monitor } \\
\text { my blood pressure at home regularly } \\
\text { every day. }\end{array}$ & 0.298 & 0.851 & 0.122 & 0.133 & 0.230 & 0.017 & 0.013 \\
\hline $\begin{array}{l}18 . I \text { am confident that I can monitor } \\
\text { my blood pressure at home in the } \\
\text { right way. }\end{array}$ & 0.098 & 0.813 & 0.152 & 0.022 & 0.129 & 0.105 & 0.117 \\
\hline $\begin{array}{l}\text { 21. No matter what the situation, I can } \\
\text { carefully monitor my blood pressure } \\
\text { according to the HBPM plan. }\end{array}$ & 0.353 & 0.765 & 0.150 & 0.226 & 0.242 & 0.041 & -0.014 \\
\hline $\begin{array}{l}\text { 31. The media (Internet, books, } \\
\text { magazines, T.V.) made me want to } \\
\text { monitor my blood pressure at home. }\end{array}$ & 0.226 & 0.162 & 0.819 & 0.182 & 0.046 & 0.074 & 0.088 \\
\hline $\begin{array}{l}\text { 33. The fellow patient's condition was } \\
\text { controlled after monitoring blood } \\
\text { pressure at home made me want to } \\
\text { monitor my blood pressure at home. }\end{array}$ & 0.247 & 0.080 & 0.797 & 0.315 & 0.033 & 0.044 & 0.066 \\
\hline $\begin{array}{l}\text { 32. The publicity from hospitals and } \\
\text { community health services made me } \\
\text { want to monitor my blood pressure at } \\
\text { home. }\end{array}$ & 0.172 & 0.260 & 0.706 & 0.115 & 0.133 & 0.033 & 0.027 \\
\hline $\begin{array}{l}40 . \text { I still monitor my blood pressure } \\
\text { regularly when I'm away. }\end{array}$ & 0.116 & 0.061 & 0.157 & 0.780 & 0.163 & -0.090 & 0.072 \\
\hline $\begin{array}{l}38 . I \text { have made specific } \\
\text { arrangements for the time and } \\
\text { recording method of HBPM. }\end{array}$ & 0.385 & 0.268 & 0.176 & 0.646 & 0.141 & 0.084 & 0.023 \\
\hline
\end{tabular}




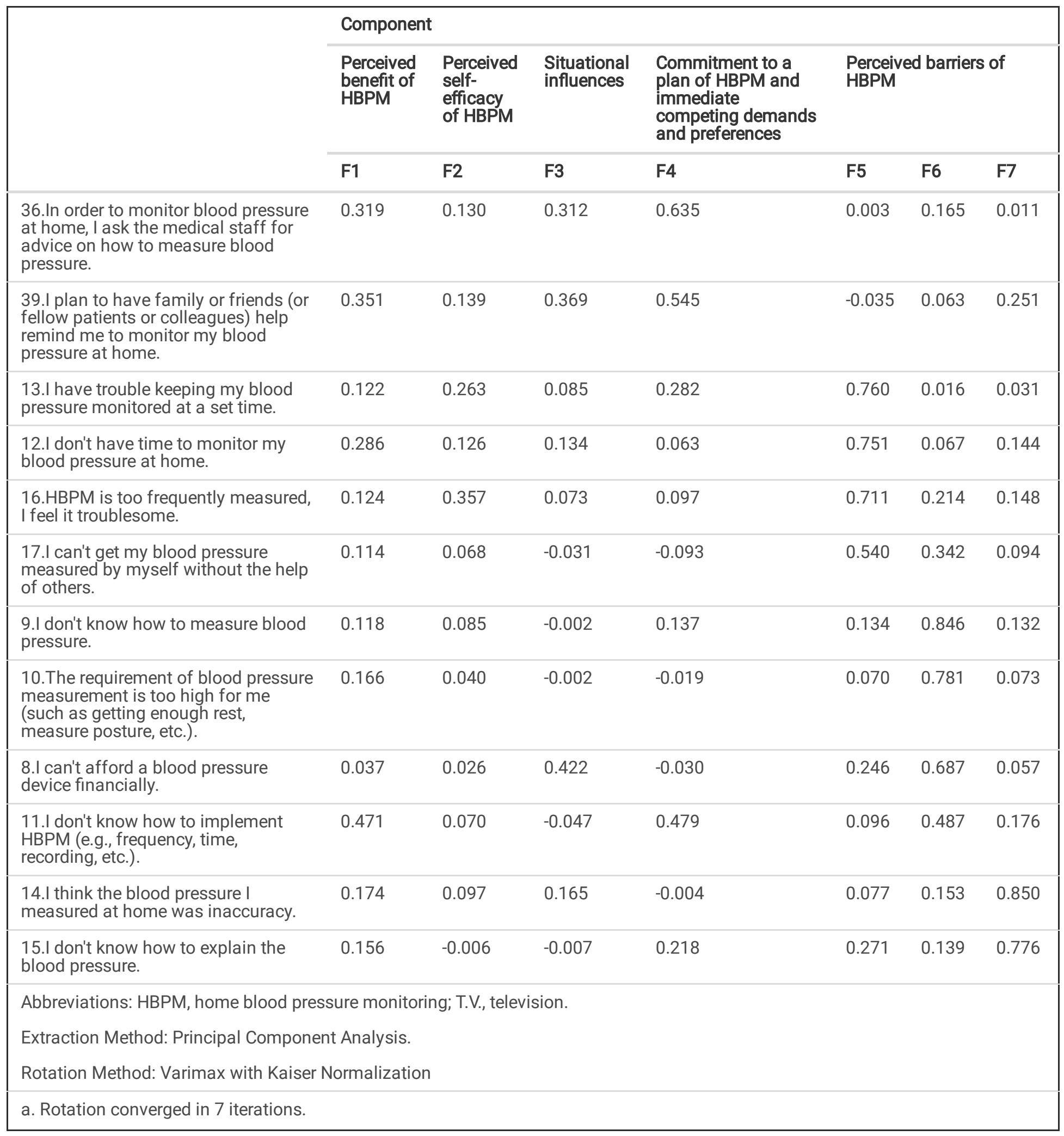

The first common factor, named perceived benefit of HBPM, included 7 items with the extracted sum of squared loadings was 5.679 , and the variance was explained by $20.283 \%$. It is used to investigate the perceived benefit of HBPM. The second common factor contained 4 items, the extracted sum of squared loadings was 3.406 , which explained $12.163 \%$ of the variation. It was named perceived self-efficacy of HBPM and is used to evaluate the self-efficacy of patients for HBPM. The third common factor was named as situational influences. It contained 3 items, the extracted sum of squared loadings was 2.605 , which accounted for $9.304 \%$ of the variation. It is mainly used to investigate the situational influences on HBPM. The fourth common factor extracted contained 4 items, with the extracted sum of squared loadings of 2.550 , which explained for $9.108 \%$ of the variation. It was named as commitment to a 
plan of HBPM and immediate competing demands and preferences. The fifth, sixth, seventh common factor extracted contained 4,4 , and 2 items, with a load of $2.541,2.442,1.600$, which explained $9.076 \%, 8.723 \%$, and $5.715 \%$ of the variation, respectively. Factors five, six and seven were related to barriers of HBPM behavior. Therefore, these 10 items were combined as one factor after expert consultation.

\section{Confirmatory Factor Analysis}

The construct validity of the scale was further verified by CFA. The fitting indexes of the model were as follows: $\chi^{2}=963.793, d f=340$, $\chi^{2} / d f=2.835, \mathrm{RMSEA}=0.092, \mathrm{CFI}=0.842$. The covariant relationships were established between the error values of item 1 and 2 , item 6 and 7, item 9 and 10, as well as item 14 and 15, according to the meaning of these items and the modification index of the model. At the same time, the model fitting index suggested that the chi-square value can effectively reduce if the covariant relationship is established between item 13 and the perceived self-efficacy of HBPM dimension, and the research group agreed that the semantic of item 13 overlapped with the self-efficacy dimension, so item 13 was deleted. The modified model fitting indexes of the final scale were as follows: $\chi^{2}=679.649, d f=310, \chi^{2} / d f=2.192$, RMSEA $=0.074, \mathrm{CFI}=0.902$. The model structure and the final 27-item scale were shown in Fig. 1 and Appendix.(Figure 1 Confirmatory Factor Analysis Model of HBPM perception scale. Abbreviations: HBPM, home blood pressure monitoring.)

\section{Scale Reliability}

Cronbach's a coefficient of the HBPM perception scale was 0.911 . The split-half reliability of the HBPM perception scale was 0.896 . The test-retest reliability coefficient of the HBPM perception scale was 0.908 . The construct reliability of dimensions ranged from 0.749 to 0.951. The reliability coefficients of each dimension were shown in Table 4.

Table 4

The reliability coefficient of each dimension and total scale

\begin{tabular}{|c|c|c|c|c|}
\hline Dimension & $\begin{array}{l}\text { Cronbach's } \\
\text { a } \\
\text { coefficient }\end{array}$ & $\begin{array}{l}\text { Split-half } \\
\text { reliability }\end{array}$ & $\begin{array}{l}\text { Test-retest } \\
\text { reliability }\end{array}$ & $\begin{array}{l}\text { Construct } \\
\text { reliability }\end{array}$ \\
\hline Perceived benefit of HBPM & 0.952 & $0.963^{\star *}$ & $0.909^{\star \star}$ & 0.951 \\
\hline Perceived self-efficacy of HBPM & 0.816 & $0.862^{* \star}$ & $0.768^{* *}$ & 0.811 \\
\hline Situational influence & 0.898 & $0.919^{* *}$ & $0.879^{* *}$ & 0.907 \\
\hline $\begin{array}{l}\text { Commitment to a plan of HBPM and immediate competing } \\
\text { demands and preferences }\end{array}$ & 0.797 & $0.624^{\star *}$ & $0.906^{* *}$ & 0.825 \\
\hline Perceived barriers of HBPM & 0.750 & $0.764^{\star *}$ & $0.829^{\star *}$ & 0.749 \\
\hline Total & 0.911 & $0.896^{* *}$ & $0.908^{* *}$ & - \\
\hline \multicolumn{5}{|l|}{ Abbreviations: HBPM, home blood pressure monitoring. } \\
\hline${ }^{* *} p<0.001$ & & & & \\
\hline
\end{tabular}

\section{Scale Validity}

The I-CVI of 27 items in this study were 1.00, S-CVI /UA was 1.00, and S-CVI / AVE was 1.00. The correlation coefficient between the score of HBPM perception scale and Self-Efficacy for Managing Chronic Disease 6-item Scale was 0.256 ( $p<0.001)$. The square root of average variance extracted of dimensions between 0.571 and 0.858 . The correlation coefficient of each dimension and the total score were shown in Table 5. Those who had their blood pressure measured at home at least once a week had higher scores on the perception scale than those who didn't (Table 6). 
Table 5

Correlation analysis between dimensions and the total amount

\begin{tabular}{|c|c|c|c|c|c|c|}
\hline Dimension & $\begin{array}{l}\text { Perceived } \\
\text { benefit of } \\
\text { HBPM }\end{array}$ & $\begin{array}{l}\text { Perceived } \\
\text { self- } \\
\text { efficacy of } \\
\text { HBPM }\end{array}$ & $\begin{array}{l}\text { Situational } \\
\text { influences }\end{array}$ & $\begin{array}{l}\text { Commitment to a plan of } \\
\text { HBPM and immediate } \\
\text { competing demands and } \\
\text { preferences }\end{array}$ & $\begin{array}{l}\text { Perceived } \\
\text { barriers } \\
\text { of HBPM }\end{array}$ & $\begin{array}{l}\text { Square } \\
\text { root of } \\
\text { AVE }\end{array}$ \\
\hline Perceived benefit of HBPM & 1 & & & & & 0.858 \\
\hline Perceived self-efficacy of HBPM & $0.298^{\star \star}$ & 1 & & & & 0.571 \\
\hline Situational influence & $0.591^{* *}$ & $0.328^{* \star}$ & 1 & & & 0.844 \\
\hline $\begin{array}{l}\text { Commitment to a plan of HBPM } \\
\text { and immediate competing } \\
\text { demands and preferences }\end{array}$ & $0.355^{*}$ & $0.095^{\star \star}$ & $0.322^{* *}$ & 1 & & 0.792 \\
\hline Perceived barriers of HBPM & $0.530^{* *}$ & $0.223^{\star \star}$ & $0.545^{\star \star}$ & $0.549^{\star \star}$ & 1 & 0.656 \\
\hline Total & $0.814^{\star \star}$ & $0.632^{* *}$ & $0.767^{\star \star}$ & $0.563^{\star *}$ & $0.746^{* \star}$ & - \\
\hline \multicolumn{7}{|c|}{ Abbreviations: HBPM, home blood pressure monitoring; AVE, average variance extracted. } \\
\hline${ }^{\star *} p<0.001$ & & & & & & \\
\hline
\end{tabular}

Table 6

The difference of perception scale scores in patients with different frequency of HBPM

\begin{tabular}{|lllll|}
\hline Variable & $\mathbf{n}$ & $\overline{\mathbf{x}} \pm$ SD & $\boldsymbol{t}$ & $\boldsymbol{p}$ \\
\hline Measure blood pressure at home at least once a week & & & 14.437 & $<0.001$ \\
\hline Yes & 287 & $103.51 \pm 11.55$ & & \\
No & 149 & $85.11 \pm 14.45$ & & \\
\hline
\end{tabular}

\section{Discussion}

Home blood pressure monitoring has been shown to improve the accuracy of hypertension burden assessment in patients with CKD, improve the blood pressure management of these patients ${ }^{18,19}$, and provide reliable data on the relationship between hypertension and prognosis ${ }^{17}$, which has great clinical value in patients with $C_{K D}{ }^{8,14-16}$. However, the cognitive and other psychological factors of HBPM are not well studied and there is a lack of specific instruments to explore the psychodynamic factors of home blood pressure monitoring behavior. In this study, we have developed a new valid and reliable scale to measure the perception of home blood pressure monitoring based on the health promotion model. The HBPM perception scale consists of 27 items covering five dimensions. It is evaluated on a Likert 5-point scale ranging from 1 (strongly disagree) to 5 (strongly agree), resulting in a final score in the range of $27 \sim$ 135.

Out of the 58 items in the item pool, 27 were retained in the finalized version. The justifications for reducing the item were as follows. First, there were 43 items retained after evaluated by experts for the relevance, importance and linguistic expression of the item.

Second, based on findings from the item analysis, there were five items with 5 or more substandard indicators, which indicated that the sensitive, differentiated and representative of these items were poor, so these items were deleted. Third, based on findings from the EFA, ten items with factor loading less than 0.40 or had a factor loading greater than 0.4 in 2 or more components were omitted. Finally, the model fitting index suggested and research group discussion agreed that the semantic of item 13 overlaps with the perceived selfefficacy of HBPM dimension, so deleted this item. Based on the findings and the health promotion model, five domains were finally identified.

HBPM perception scale is a reliable and valid instrument to assess the perception of HBPM. Firstly, the data analysis results demonstrated it had reasonable reliability ${ }^{40,44}$. The Cronbach's a coefficient for total scale was 0.911 and ranged from 0.750 to 0.952 . The split-half reliability was 0.896 for total scale and $0.624 \sim 0.963$ for five dimensions. And the test-retest reliability for total scale was 
0.908 ranged $0.829 \sim 0.909$. The construct reliability of dimensions ranged from 0.749 to 0.951 . Secondly, the results showed that the HBPM perception scale had reasonable validity $40,42,43$. The HBPM perception scale total score was positively correlated with the SelfEfficacy for Managing Chronic Disease 6-item Scale, suggesting that criterion-related validity was reasonable. Confirmatory factor analysis showed the model fit well: $\chi^{2}=679.649, d f=310, \chi^{2} / d f=2.192$, RMSEA $=0.074, \mathrm{CFI}=0.902$. The I-CVI of 27 items in this study was 1.00 , the scale-level content validity index (universal agreement) was 1.00 , and the scale-level content validity index(average) was 1.00. The square root of average variance extracted of dimensions between 0.571 and 0.858 . For patients who measured their blood pressure at home at least once a week or not, the scale could detect differences in scores, indicating that the scale can predict HBPM behavior well.

According to the analysis results, five domains were finally identified, and this factor structure derived from the health promotion model. The health promotion model puts forward ten categories of factors that influence health promotion behaviors. Our study demonstrates that the following five factors were predictors of HBPM behavior among CKD patients.

The dimension of perceived benefits of HBPM consists of 7 items. The perceived benefits of a certain behavior can directly promote an individual to adopt this behavior according to the health promotion model ${ }^{34}$. Data from 436 patients demonstrated this structure. And some results obtained in previous studies were retained. For example, the item "Home blood pressure is a good indicator of how my blood pressure fluctuates" was developed based on a study in Singapore ${ }^{25}$. These items are representative and can be used to assess the perceived benefit of HBPM behavior.

The perceived barriers of HBPM dimension contains 9 items. Individuals often avoid behaviors that they feel are more difficult to implement ${ }^{34}$. In terms of HBPM behavior, patients are more likely to avoid it because it involves barriers such as measurement equipment ${ }^{25}$, time ${ }^{26}$, and method ${ }^{45}$. Our study found that these barriers, which have been demonstrated in patients with hypertension, are also present in patients with CKD. For instance, items "I don't have time to monitor my blood pressure at home", "I don't know how to measure blood pressure" remained after data analysis. Attention should be paid in clinical practice to identify and help patients overcome the barriers of HBPM behavior.

The dimension of perceived self-efficacy of HBPM includes 4 items. Individuals with high self-efficacy are more likely to maintain healthy behaviors and engage in them frequently ${ }^{36}$. Two qualitative studies embedded within the randomized controlled trials in the U.K. have shown that patients undergoing HBPM are confident in self-monitoring blood pressure ${ }^{27,28}$. However, for HBPM, regularly, long-term, and accurately measure blood pressure is needed if its clinical value is to be brought into play. Therefore, this study developed items based on these three aspects, and data analysis also proved that perceived self-efficacy of HBPM plays an important role in HBPM behavior in patients with CKD. On the basis of previous studies and combined with the characteristics of HBPM, our study further refined the perceived self-efficacy of HBPM, so as to comprehensively reflect the self-efficacy of HBPM perceived by patients, and provide reference for clinical practice.

The situational influences dimension consists of 3 items. Individuals often want their behavior to be consistent with the behavior of others in a given situation ${ }^{46}$. One study showed that putting up posters about HBPM in health care facilities increased the use of HBPM for hypertension patients ${ }^{47}$. In this study, the items were developed mainly based on this result, and analysis of 436 cases of data also confirmed that situational influences are also important for HBPM behavior in patients with chronic kidney disease. The use of HBPM needs to be encouraged by setting up situations, such as health talks and more publicity.

The dimension of commitment to a plan of HBPM and immediate competing demands and preferences contains 4 items. A commitment to a plan of action is one's own plan to perform a certain behavior, and immediate competing demands and preferences are the various contingencies of a healthy behavior plan ${ }^{46}$. Making a plan is an important step before start acting. Individuals may have immediate competing demands and preferences before performing a planned health behavior, and the attraction or stress brought by such emergencies can affect individuals' health behavior ${ }^{34}$. Our study confirmed that this factor could affect the HBPM behavior in patients with CKD. It is necessary to help patients develop HBPM plan and adjust the plan flexibly for patients with special conditions.

HBPM perception scale is a reliable and sensitive quantitative instrument, which adopts the health promotion model as the cause pattern that can assist medical personnel in evaluating the determinants of HBPM behavior from the patient's perspective. For the patients who reluctant to perform HBPM according to recommendation, the scale can help clinical medical staff to find out the potential problems that patients will encounter during HBPM, so as to take preventive and targeted measures to help patients overcome the problems. In the case of patients with irregular monitoring, it can help to find the reasons for non-standard monitoring and then 
develop personalized strategies, so as to improve the clinical work efficiency and reduce the workload of clinical medical staff. It can also be used in clinical studies to help to identify intervention targets and establish intervention strategies to improve the monitoring rate of patients' home blood pressure, and effectively predict the HBPM behavior and health outcome of HBPM intervention.

There are some limitations of this study. Although the patients with stage 1-5 CKD were investigated, the subjects were mainly hemodialysis patients. Future studies need to further explore the validity and reliability of the HBPM perception scale in non-dialysis patients and peritoneal dialysis patients. Meanwhile, the sample of this study was only recruited in two tertiary hospitals from Guangdong, China. This might limit the generalizability of the findings. Therefore, future studies need to assess the psychometrics features of the HBPM perception scale in different samples with different cultural and socio-economic status.

\section{Conclusions}

The HBPM perception scale provides a valid and reliable instrument for assessing the perception of HBPM. Besides, the items are straightforward and easy for users to understand and use. In addition to enriching our understanding of home blood pressure monitoring among patients, the HBPM perception scale is also useful in establishing a possible link between assessment and health education and helpful in developing appropriate training programs and evaluating the effectiveness of HBPM intervention program to improve blood pressure management in these patients and finally reduce the risk of cardiovascular events.

\section{Abbreviations}

HBPM: Home blood pressure monitoring

CKD: Chronic kidney disease

CFA: Confirmatory factor analysis

EFA: Exploratory factor analysis

HPM: Health promotion model

I-CVI: Item-level content validity index

C.V.: Coefficient of variation

C.R.: Critical ratio

CITC: Corrected item-total correlation

KMO: Kaiser-Meyer-Olkin

PCA: Principal component analysis

\section{Declarations}

\section{Ethics approval}

This study was performed in accordance with the Declaration of Helsinki and was approved by the ethics and academic committee of Sun Yat-sen University.

\section{Consent for publication}

Not applicable.

\section{Availability of data}

The datasets used and/or analysed during the current study are available from the corresponding author on reasonable request.

\section{Conflict of interest}


The authors declare no conflicts of interest exist.

\section{Funding}

The study was funded by Nature Science Foundation of Guangdong (No. 2018A030313514) and Science and Technology Planning Project of Guangdong (No. 2017ZC0028).

\section{Authorship}

All authors contributed to the study design, or data collect, or data research and interpretation; and read and approved the content of the manuscript and take responsibility for all aspects of the work.

\section{Acknowledgements}

We sincerely thank all the participants and staffs who have made valuable contributions to this research.

\section{References}

1. Hill NR, Fatoba ST, Oke JL, et al. Global Prevalence of Chronic Kidney Disease - A Systematic Review and Meta-Analysis. PloS one. 2016;11(7):e0158765.

2. Zhang L, Wang F, Wang L, et al. Prevalence of chronic kidney disease in China: a cross-sectional survey. Lancet. 2012;379(9818):815-22.

3. Wang S, Chen R, Liu Q, Shu Z, Zhan S, Li L. Prevalence, awareness and treatment of chronic kidney disease among middle-aged and elderly: The China Health and Retirement Longitudinal Study. Nephrology (Carlton). 2015;20(7):474-84.

4. GBD 2013 Mortality and Causes of Death Collaborators. Global, regional, and national age-sex specific all-cause and causespecific mortality for 240 causes of death, 1990-2013: a systematic analysis for the Global Burden of Disease Study 2013. Lancet. 2015;385(9963):117-71.

5. ANZDATA Australia and New Zealand Dalysis and Transplant Registry. http://www.anzdata.org.au/v1/report_2017.html. Accessed 13 Aug 2018.

6. Muntner P, Anderson A, Charleston J, et al. Hypertension awareness, treatment, and control in adults with CKD: results from the Chronic Renal Insufficiency Cohort (CRIC) Study. Am J Kidney Dis. 2010;55(3):441-51.

7. Zheng Y, Cai GY, Chen XM, et al. Prevalence, awareness, treatment, and control of hypertension in the non-dialysis chronic kidney disease patients. Chin Med J (Engl). 2013;126(12):2276-80.

8. Writing Group of 2018 Chinese Guidelines for the Management of Hypertension. 2018 Chinese Guidelines for the Management of Hypertension. Chin J Cardiol. 2019;24(1):24-56.

9. Sarafidis PA, Li S, Chen SC, et al. Hypertension awareness, treatment, and control in chronic kidney disease. Am J Med. 2008;121(4):332-40.

10. Kidney Disease Outcomes Quality Initiative. K/DOQI clinical practice guidelines on hypertension and antihypertensive agents in chronic kidney disease. Am J Kidney Dis. 2004;43;5 Suppl 1:S1-290.

11. Eskridge MS. Hypertension and chronic kidney disease: the role of lifestyle modification and medication management. Nephrol Nurs J. 2010;37(1):55-60, 99.

12. Doyle-Campbell C. European Society of Hypertension and European Society of Cardiology guidelines and the muted enthusiasm for home blood pressure monitoring. Hypertension. 2014;63(2):e5.

13. Ma R, Wang Q, Li N, et al. Home Blood Pressure Monitoring Improved Safety in Patients with Severe Hypertension. J Hypertens.2016;34:e66.

14. James PA, Oparil S, Carter BL, et al. 2014 evidence-based guideline for the management of high blood pressure in adults: report from the panel members appointed to the Eighth Joint National Committee (JNC 8). JAMA. 2014;311(5):507-20.

15. Imai Y, Kario K, Shimada K, et al. The Japanese Society of Hypertension Guidelines for Self-monitoring of Blood Pressure at Home (Second Edition). Hypertens Res. 2012;35(8):777-95.

16. Parati G, Stergiou GS, Asmar R, et al. European Society of Hypertension practice guidelines for home blood pressure monitoring. J Hum Hypertens. 2010;24(12):779-85. 
17. Pickering TG, Miller NH, Ogedegbe G, Krakoff LR, Artinian NT, Goff D. Call to action on use and reimbursement for home blood pressure monitoring: Executive Summary. A joint scientific statement from the American Heart Association, American Society of Hypertension, and Preventive Cardiovascular Nurses Association. J Clin Hypertens (Greenwich). 2008;10(6):467-76.

18. Grant S, Greenfield SM, Nouwen A, McManus RJ. Improving management and effectiveness of home blood pressure monitoring: a qualitative UK primary care study. Br J Gen Pract. 2015;65(640):e776-83.

19. Carrera PM, Lambooij MS. Implementation of Out-of-Office Blood Pressure Monitoring in the Netherlands: From Clinical Guidelines to Patients' Adoption of Innovation. Medicine. 2015;94(43):e1813.

20. Ostchega Y, Zhang G, Kit BK, Nwankwo T. Factors Associated With Home Blood Pressure Monitoring Among US Adults: National Health and Nutrition Examination Survey, 2011-2014. Am J Hypertens. 2017;30(11):1126-32.

21. Cuspidi C, Meani S, Fusi V, et al. Home blood pressure measurement and its relationship with blood pressure control in a large selected hypertensive population. J Hum Hypertens. 2004;18(10):725-31.

22. Cuspidi C, Meani S, Lonati L, et al. Prevalence of home blood pressure measurement among selected hypertensive patients: results of a multicenter survey from six hospital outpatient hypertension clinics in Italy. Blood Press. 2005;14(4):251-6.

23. Poon IO, Etti N, Lal LS. Does the use of home blood pressure monitoring vary by race, education, and income? Ethn Dis. 2010;20(1):2-6.

24. Viera AJ, Cohen LW, Mitchell CM, Sloane PD. Use of home blood pressure monitoring by hypertensive patients in primary care: survey of a practice-based research network cohort. J Clin Hypertens (Greenwich). 2008;10(4):280-6.

25. Tan NC, Khin LW, Pagi R. Home blood-pressure monitoring among hypertensive patients in an Asian population. J Hum Hypertens. 2005;19(7):559-64.

26. McGowan N, Padfield PL. Self blood pressure monitoring: a worthy substitute for ambulatory blood pressure? J Hum Hypertens. 2010;24(12):801-6.

27. Hanley J, Ure J, Pagliari C, Sheikh A, McKinstry B. Experiences of patients and professionals participating in the HITS home blood pressure telemonitoring trial: a qualitative study. BMJ open. 2013;3(5):e002671.

28. Jones MI, Greenfield SM, Bray EP, et al. Patients' experiences of self-monitoring blood pressure and self-titration of medication: the TASMINH2 trial qualitative study. Br J Gen Pract. 2012;62(595):e135-42.

29. Port K, Palm K, Viigimaa M. Daily usage and efficiency of remote home monitoring in hypertensive patients over a one-year period. J Telemed Telecare. 2005;11 Suppl 1:34-6.

30. Rickerby J, Woodward J. Patients' experiences and opinions of home blood pressure measurement. J Hum Hypertens. 2003;17(7):495-503.

31. Wu TY, Pender N. A panel study of physical activity in Taiwanese youth: testing the revised health-promotion model. Fam Community Health. 2005;28(2):113-24.

32. Pender NJ , Murdaugh CL , Parsons MA. Health promotion in nursing practice. New York: Pearson; 2011.

33. McCullagh M, Lusk SL, Ronis DL. Factors influencing use of hearing protection among farmers: a test of the pender health promotion model. Nurs Res. 2002;51(1):33-9.

34. Mehrabbeik A, Mahmoodabad SSM, Khosravi HM, Fallahzadeh H. Breakfast consumption determinants among female high school students of Yazd Province based on Pender's Health Promotion Model. Electron Physician. 2017;9(8):5061-7.

35. Pullen C, Walker SN, Fiandt K. Determinants of health-promoting lifestyle behaviors in rural older women. Fam Community Health. 2001;24(2):49-72.

36. Wu T-Y, Pender N. Determinants of physical activity among Taiwanese adolescents: An application of the health promotion model. Res Nurs Health. 2002;25(1):25-36.

37. Wang Y, Li K, Li H, Zhao W, Zheng J. Development, Reliability, and Validity of the Home Blood Pressure Monitoring Adherence Scale for Patients with Chronic Kidney Disease. Patient Prefer Adherence. 2020;14:1863-72.

38. Lorig KR, Sobel DS, Ritter PL, Laurent D, Hobbs M. Effect of a self-management program on patients with chronic disease. Eff Clin Pract. 2001;4(6):256-62.

39. Hao YT, Sun XF, Fang JQ. The Study of Statistical Methods Used for Item Selection. Chinese Journal of Health Statistics. 2004;21(4):209-11.

40. Wu ML. Questionnaire statistical analysis practice:SPSS operation and application. Chongqing: Chongqing university press; 2010. 
41. He QY, Wang J, Zhang YL, Wang SH, Yang G. Item screening technique on clinical outcome rating scale which based on patientreported outcomes. China Journal of Traditional Chinese Medicine Pharmacy. 2011;026(001):112-4.

42. Shi J, Mo X, Sun Z. Content validity index in scale development. Zhong Nan Da Xue Xue Bao Yi Xue Ban. 2012;37(2):152-5.

43. Wu ML. Structural equation model: operation and application of AMOS. Chongqing: Chongqing university press; 2010.

44. DeVellis RF. Scale Development : Theory and Applications. London: Sage; 1991.

45. Nasothimiou EG, Karpettas N, Dafni MG, Stergiou GS. Patients' preference for ambulatory versus home blood pressure monitoring. J Hum Hypertens. 2014;28(4):224-9.

46. Dehdari T, Rahimi T, Aryaeian N, Gohari MR, Esfeh JM. Developing and testing a measurement tool for assessing predictors of breakfast consumption based on a health promotion model. J Nutr Educ Behav. 2014;46(4):250-8.

47. Milot JP, Birnbaum L, Larochelle P, et al. Unreliability of home blood pressure measurement and the effect of a patient-oriented intervention. Can J Cardiol. 2015;31(5):658-63.

\section{Appendix}

Appendix: Home Blood Pressure Monitoring Perception Scale 


$\begin{array}{llllll}\text { Item } & 1 & 2 & 3 & 4 & 5 \\ & \begin{array}{l}\text { Strongly } \\ \text { disagree }\end{array} & \text { Disagree } & \text { Neutrality } & \text { Agree } & \begin{array}{l}\text { Strongly } \\ \text { agree }\end{array} \\ & & & \end{array}$

Perceived benefit of HBPM

1. Home blood pressure monitoring (HBPM) is a good indicator of how my blood pressure fluctuates.

2.HBPM helps me control blood pressure.

3.HBPM helps me take my medicine as directed.

4.HBPM made me feel like I was working with my doctor to decide on a treatment.

5.HBPM helps control my disease (such as reducing my risk of coronary heart disease or stroke).

6.HBPM can improve my quality of life.

7.HBPM helps me adjust my lifestyle (diet, exercise, etc.).

Perceived barriers of HBPM

8.I can't afford a blood pressure device financially.

9.I don't know how to measure blood pressure.

10.The requirement of blood pressure measurement is too high for me (such as getting enough rest, measure posture, etc.).

11.I don't know how to implement HBPM (e.g., frequency, time, recording, etc.).

12.I don't have time to monitor my blood pressure at home.

13.I think the blood pressure I measured at home was inaccuracy.

14.I don't know how to explain the blood pressure.

15. HBPM is too frequently measured, I feel it troublesome.

16..I can't get my blood pressure measured by myself without the help of others.

Perceived self-efficacy of HBPM

17.I am confident that I can monitor my blood pressure at home in the right way.

18.I am confident that I can monitor my blood pressure at home regularly every day.

19.I am confident that I will be able to monitor my blood pressure at home for the long term.

20.No matter what the situation, I can carefully monitor my blood pressure according to the HBPM plan.

Situational influences

21. The media (Internet, books, magazines, T.V.) made me want to monitor my blood pressure at home.

22. The publicity from hospitals and community health services made me want to monitor my blood pressure at home.

23.The fellow patient's condition was controlled after monitoring blood pressure at home made me want to monitor my blood pressure at home.

Commitment to a plan of HBPM and immediate competing demands and preferences

24. In order to monitor blood pressure at home, I ask the medical staff for advice on how to measure blood pressure. 
26. I plan to have family or friends (or fellow patients or colleagues) help remind me to monitor my blood pressure at home.

27.I still monitor my blood pressure regularly when I'm away.

\section{Figures}

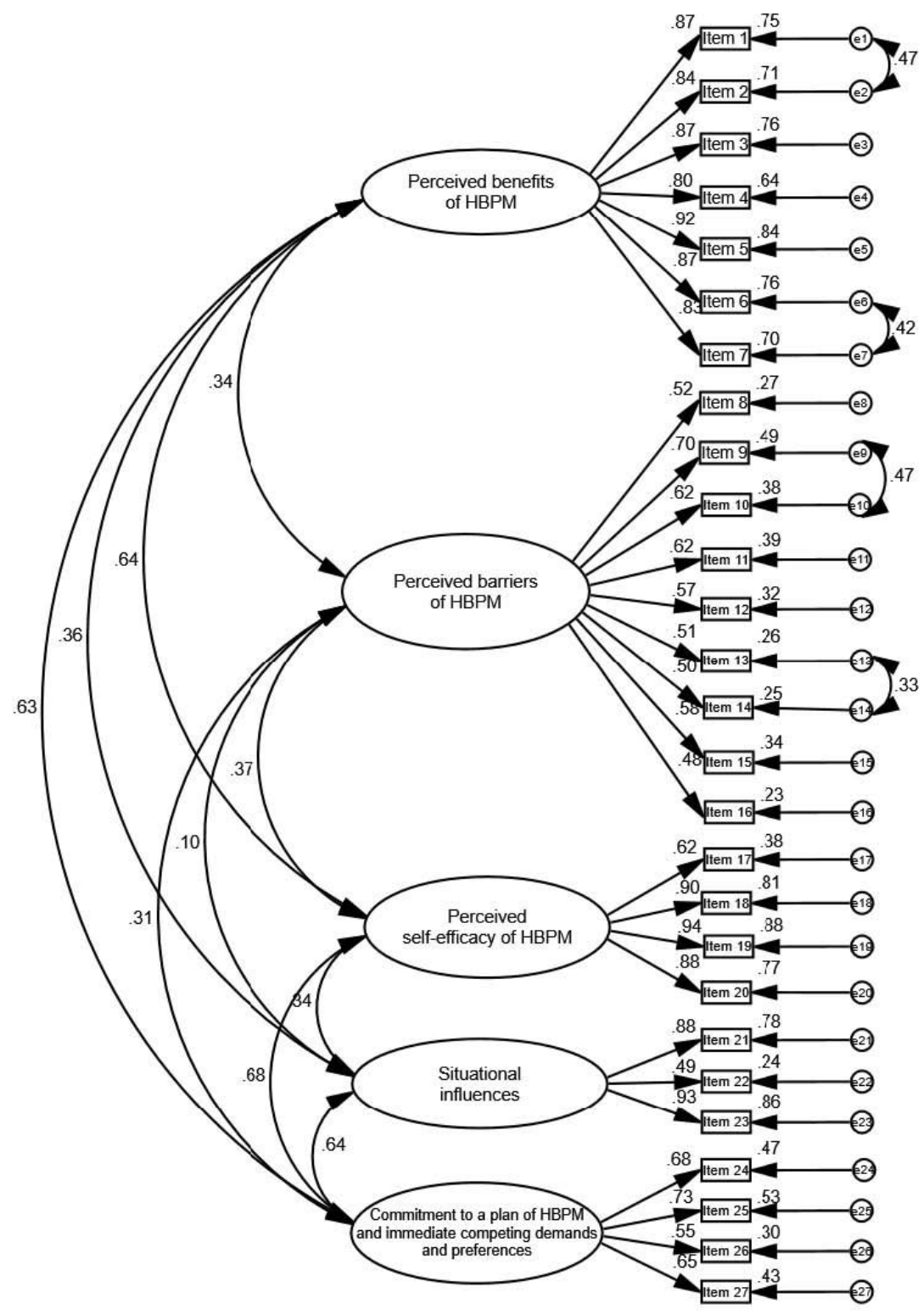

Figure 1

Confirmatory Factor Analysis Model of HBPM perception scale. Abbreviations: HBPM, home blood pressure monitoring. 